\title{
Primary decompressive craniectomy in poor-grade aneurysmal subarachnoid hemorrhage: long-term outcome in a single-center study and systematic review of literature
}

\author{
Simon Brandecker ${ }^{1}$ (D) Alexis Hadjiathanasiou ${ }^{1} \cdot$ Tamara Kern $^{1} \cdot$ Patrick Schuss $^{1} \cdot$ Hartmut Vatter $^{1} \cdot$ Erdem $_{\text {Güresir }}{ }^{1}$
}

Received: 15 May 2020 / Revised: 16 July 2020 / Accepted: 1 September 2020 / Published online: 12 September 2020

(C) The Author(s) 2020

\begin{abstract}
Primary decompressive craniectomy (PDC) in patients with poor-grade aneurysmal subarachnoid hemorrhage (aSAH) in order to decrease elevated intracranial pressure (ICP) is controversially discussed. The aim of this study was to analyze the effect of PDC on long-term clinical outcome in these patients in a single-center cohort and to perform a systematic review of literature. Eightyseven consecutive poor-grade SAH patients (World Federation of Neurosurgical Societies (WFNS) grades IV and V) were analyzed between October 2012 and August 2017 at the author's institution. PDC was performed due to clinical signs of herniation or brain swelling according to the treating surgeon. Outcome was analyzed according to the modified Rankin Scale (mRS). Literature was systematically reviewed up to August 2019, and data of poor-grade aSAH patients who underwent PDC was extracted for statistical analyses. Of 87 patients with poor-grade aSAH in the single-center cohort, 38 underwent PDC and 49 did not. Favorable outcome at 2 years post-hemorrhage did not differ significantly between the two groups (26\% versus $20 \%$ ). Systematic literature review revealed 9 studies: Overall, a favorable outcome could be achieved in nearly half of the patients (49\%), with an overall mortality of $24 \%$ (median follow-up 11 months). Despite a worse clinical status at presentation (significantly higher rate of mydriasis and additional $\mathrm{ICH}$ ), poor-grade aSAH patients with PDC achieve favorable outcome in a significant number of patients. Therefore, treatment and PDC should not be omitted in this severely ill patient collective. Prospective controlled studies are warranted.
\end{abstract}

Keywords Aneurysmal subarachnoid hemorrhage · Primary decompressive craniectomy · Long-term outcome

\section{Introduction}

Patients who present with a poor-grade aneurysmal subarachnoid hemorrhage (aSAH) according to the World Federation of Neurosurgical Societies (WFNS grades IV and V) often have a poor prognosis with high case fatality and disability rates [4, 7, 23, 37]. In aSAH severely brain swelling can occur primarily due to initial tissue damage with or without additional intracerebral hemorrhage and secondarily due to vasospasm/infarction. Brain swelling and elevated intracranial pressure (ICP) are known to worsen outcome following

Simon Brandecker

simon.brandecker@ukbonn.de

1 Department of Neurosurgery, Rheinische

Friedrich-Wilhelms-University Bonn, Venusberg-Campus 1,

53127 Bonn, Germany
SAH $[5,10,15]$. Additionally significant predictors of unfavorable outcome in patients with poor-grade aSAH are patient age, WFNS grade V, signs of cerebral herniation, aneurysm size, and space-occupying hematoma [28]. Elderly patients suffering from aSAH should be considered for treatment despite age [32]. Decompressive craniectomy (DC) after traumatic brain injury (TBI) and space occupying stroke has been shown to reduce elevated ICP and improves outcome after ischemic stroke $[1,11,29,35]$. To check the hypothesis that DC could improve outcome in aSAH patients similar to improve outcome in patients with space-occupying stroke, the effect of DC in poor-grade aSAH patients was reported in multiple studies: The role of aggressive surgical treatment option such as PDC remains controversial [3, 6, 8, 9, 12, 13, 16-19, 21, 22, 24-27, 30, 33, 34, 36, 38]. A systematic review and meta-analysis has shown that the effect of DC on functional outcome versus that of other interventions for refractory intracranial hypertension is still unknown [2]. 
We hypothesized that an early decompressive craniectomy may result in an improved neurological outcome in this severely ill subset of patients due to early control of elevated ICP, and we reported our experience with the effect of PDC on clinical outcome with long-term follow-up. A comparison was performed with a control group of poor-grade aSAH patients treated without PDC but, if necessary, receiving a secondary decompressive craniectomy due to cerebral infarction or as a treatment for increased ICP.

Additionally, we performed a systematic review of literature for PDC in poor-grade aSAH patients and therefore extracted relevant data of this subgroup of patients to clarify a possible benefit of an early decompression on clinical outcome in these patients.

\section{Material and methods}

\section{Patient population}

Between October 2012 and August 2017, a total number of 87 consecutive poor-grade (WFNS grade IV and V) aSAH patients were treated at our institution (Fig. 1). All of these treated patients were included for further analysis. Patients were excluded if they presented as WFNS grades I-III on admission. The diagnosis of SAH was confirmed by emergency computed tomography (CT) scanning and additional CTangiography (CT-A). All patients underwent digital subtraction angiography (DSA) immediately after stabilization. In each case, the treatment decision (clipping or coiling) was based on an interdisciplinary approach.

PDC was performed according to the decision of the officiating neurovascular neurosurgeon. Decision-making was

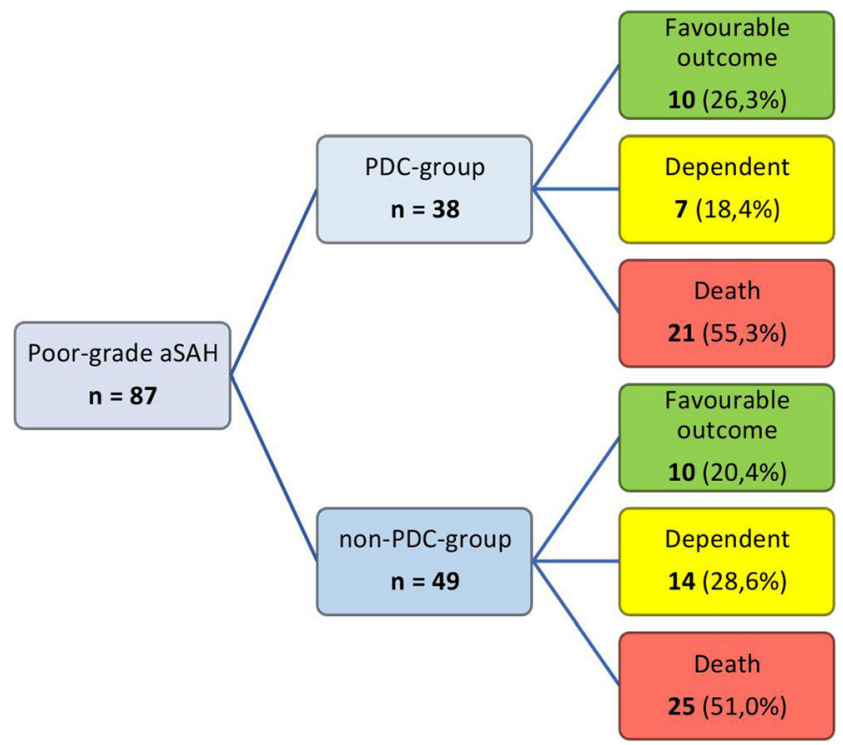

Fig. 1 Flowchart of poor-grade aSAH patients with and without PDC and their long-term neurological outcome after 2 years based on clinical signs of herniation or brain swelling, presence of large intracerebral hematoma (ICH), and/or intraoperative evidence of brain swelling $[6,18,27]$.

Eventually, PDC was performed in 38 patients (PDC group) - either simultaneously within aneurysm clipping procedure or, in 2 cases, immediately after endovascular treatment.

Included for the control group (non-PDC group) were all other poor-grade aSAH patients treated in the same period of time, who did not undergo PDC (49 patients). A secondary decompressive craniectomy in this group was performed in case of treatment for refractory-elevated intracranial pressure (ICP) as ultima ratio therapy.

Best medical treatment according to the current guidelines $[7,31]$ was targeted in both treatment groups. Time of mechanical ventilation and length of stay on intensive care unit (ICU) were collected routinely.

\section{Decompressive craniectomy and intensive care unit therapy management}

DC was performed by removing a large (at least $12 \times 15 \mathrm{~cm}$ ) fronto-temporo-parieto-occipital bone flap. The temporal bone was removed osteoclastically down to the base of the middle fossa, and the dura was opened widely in a stellate fashion to minimize dural tension as described before [14]. The bone flap was cryoconserved at $-80^{\circ} \mathrm{C}$, and cranioplasty was performed approximately 3 months after DC. Exemplary CT scans are shown in Fig. 2.

After DC, all of the patients were transferred to ICU for postoperative therapy. To assess procedural complications, CT scan was performed routinely $24-36 \mathrm{~h}$ after aneurysm surgery or endovascular aneurysm treatment. ICP was monitored with external ventricular drain (EVD) or intraparenchymal ICP probe (Spiegelberg). Increased ICP was treated with intermittent cerebrospinal fluid (CSF) drainage, mild hyperventilation, and osmotherapy. Nimodipine was administered for 21 days after ictus $(6 \times 60 \mathrm{mg}$ /day); transcranial Doppler (TCD) ultrasound was performed daily in all patients. At patients who underwent aneurysm clipping, a routinely postoperative DSA was performed 7-10 days after the surgery.

\section{Outcome measurements}

The patients underwent routine follow-up, and outcome was assessed according to the modified Rankin Scale (mRS) at 6 months, at 1 year, and at 2 years post-hemorrhage. For further analysis, outcome was dichotomized into favorable (mRS 0-3) versus unfavorable (mRS 4-6) outcome according to previous trials on the effect of decompressive craniectomy in the course of malignant infarction [20]. 
Fig. 2 CT scans of a 21-year-old WFNS grade 5 aSAH-patient: preoperative scan (a), $24 \mathrm{~h}$-scan after clipping and PDC (b), and after cranioplasty 3 months later (c)

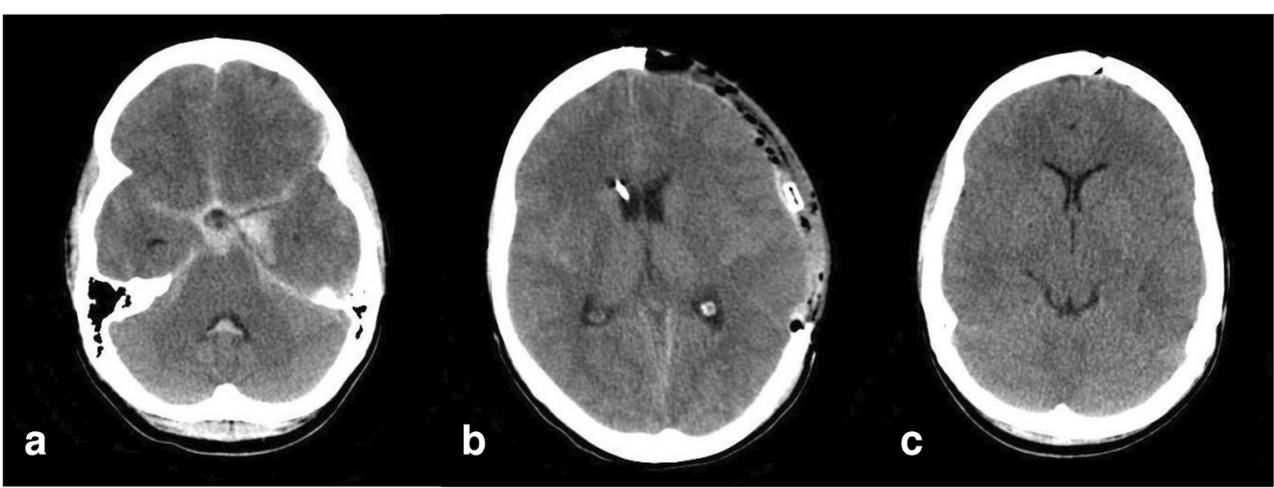

\section{Matched-pair analysis}

To exclude confounding factors with impact on outcome [20], we performed a matched-pair analysis. Matching parameters were age, admission status (according to WFNS grade), Fisher scale, and the presence of an additional intraventricular and/or intracerebral hematoma (IVH or ICH) (Table 3).

\section{Statistics}

Patient characteristics including size, localization, and treatment of aneurysm; presence of intracerebral hematoma (ICH); signs of cerebral herniation (i.e., anisocoria and bilateral pupil dilatation); radiological features; use of anticoagulation or antiplatelet drugs; and functional outcome were prospectively entered in an SPSS database (version 24.0, IBM Corp., Armonk, NY). Statistical analyses were performed with an unpaired $t$ test for continuous variables; categorical variables were analyzed in contingency tables using the Fisher's exact test. Adjusted odds ratio (OR) and $95 \%$ confidence interval (CI) were calculated. Results with $p<0.05$ were considered statistically significant.

\section{Systematic literature review}

A search was designed to identify relevant articles on PDC in poor-grade aSAH. A comprehensive literature search was performed on MEDLINE (PubMed) database up to August 2019. The medical subject headings were (used in combination with "subarachnoid hemorrhage" and "aneurysmal subarachnoid hemorrhage") "decompressive craniectomy," "hemicraniectomy," and "decompression + craniectomy." One author (S.B.) screened title and abstract from the search results and scrutinized the references of the included publications for additional studies. Two authors (S.B. and E.G.) independently read full text of eligible studies and a consensus on which studies to include was reached after discussion among the two authors (S.B. and E.G.) considering the following inclusion and exclusion criteria.
In order to clarify the effect of an early decompressive craniectomy (PDC) on functional outcome in poor-grade aSAH patients, only studies have been included, in which the following individual patient data could be extracted out of the original publication: (1) Patients with WFNS or Hunt and Hess grade IV or V on admission underwent an early decompressive craniectomy (mainly $<24 \mathrm{~h}$ after ictus). (2) Functional outcome data had to be collected in $100 \%$ of the patients (except death). (3) The earliest captured outcome had to be 3 months after hemorrhage. The including criteria are summarized in Fig. 3.

In case of multiple publications from the same author/ institution on the same topic in the same period of time, the most relevant article was elected in order to avoid inclusion of overlapping patients. Outcome was assessed by modified Rankin Scale (mRS), Glasgow Outcome Scale (GOS), or extended Glasgow Outcome Scale (GOSE). We dichotomized functional outcome as favorable (mRS $1-3$, GOS 4-5, and GOSE 5-8) versus unfavorable (mRS 4-6, GOS $1-3$, and GOSE 1-4). In every study included, the context between WFNS (or Hunt and Hess) grade on admission, PDC as treatment modality, and long-term neurological outcome had to be extractable.

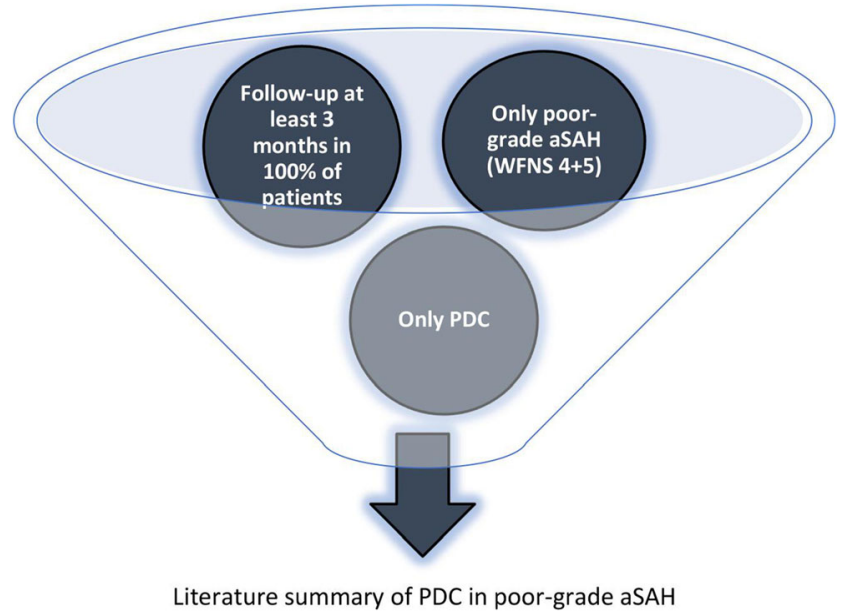

Fig. 3 Including criteria for literature summary 
Studies, in which the authors could not extract these detailed patient data from the original publication, were excluded from the analysis. The other exclusion criteria were the following: single case reports, conference abstracts, and studies including non-aneurysmal SAH.

A flowchart depicting the search strategy of systematic literature review is shown in Fig. 4.

\section{Results}

\section{Patient characteristics}

Between October 2012 and August 2017, 38 patients with poor-grade aSAH underwent PDC (PDC group). Mean age was 54 years ( \pm 12 years), among them 28 female patients (74\%). During the same period, 49 patients with poor-grade aSAH did not undergo PDC (non-PDC group). Mean age was 61 years ( \pm 11 years), among them 34 female patients $(69 \%)$. The baseline characteristics of the patients of both groups are given in Table 1. Microsurgical clipping was performed in 36 of 38 patients (95\%) in the PDC group compared with 8 of 49 patients $(16 \%)$ in the non-PDC group $(p<0.0001)$.

A secondary decompressive craniectomy (SDC) in the non-PDC group was performed in 14 patients $(29 \%)$ in case of treatment for refractory elevated ICP as ultima ratio therapy.

\section{Patients in the PDC group had a significantly worse clinical status at presentation}

Twenty-six of thirty-eight patients $(68 \%)$ in the PDC group were presenting with additional ICH compared with thirteen of forty-nine patients $(27 \%)$ in the non-PDC group ( $p=$ $0.0002)$. Twenty-two of thirty-eight patients $(58 \%)$ in the PDC group had clinical signs of cerebral herniation at presentation (uni- or bilateral dilated pupil), compared with thirteen of forty-nine patients (27\%) in the non-PDC group ( $p=$ $0.0042)$. Thirty-three of thirty-eight patients $(87 \%)$ in the PDC group presented as WFNS grade 5 on admission compared with thirty-two of forty-nine patients $(65 \%)$ in the nonPDC group $(p=0.03)$.

The most frequent localization of the ruptured aneurysm in the PDC group was the middle cerebral artery (MCA, 42\%), followed by the internal carotid artery (ICA, 26\%). In the nonPDC group, the most frequent localization was the anterior communicating artery (ACoA, 35\%). Patients treated with PDC had significantly larger aneurysms (mean size $12 \mathrm{~mm}$ $( \pm 8 \mathrm{~mm})$ versus $8 \mathrm{~mm}( \pm 6 \mathrm{~mm}) ; p=0.01)$ assessed by DSA. There were three giant aneurysms ( $\geq 25 \mathrm{~mm}$ ) in PDC group $(8 \%)$ and two in the non-PDC group (4\%); $p=0.65$. Multi
Fig. 4 Flowchart depicting the search strategy of systematic literature review

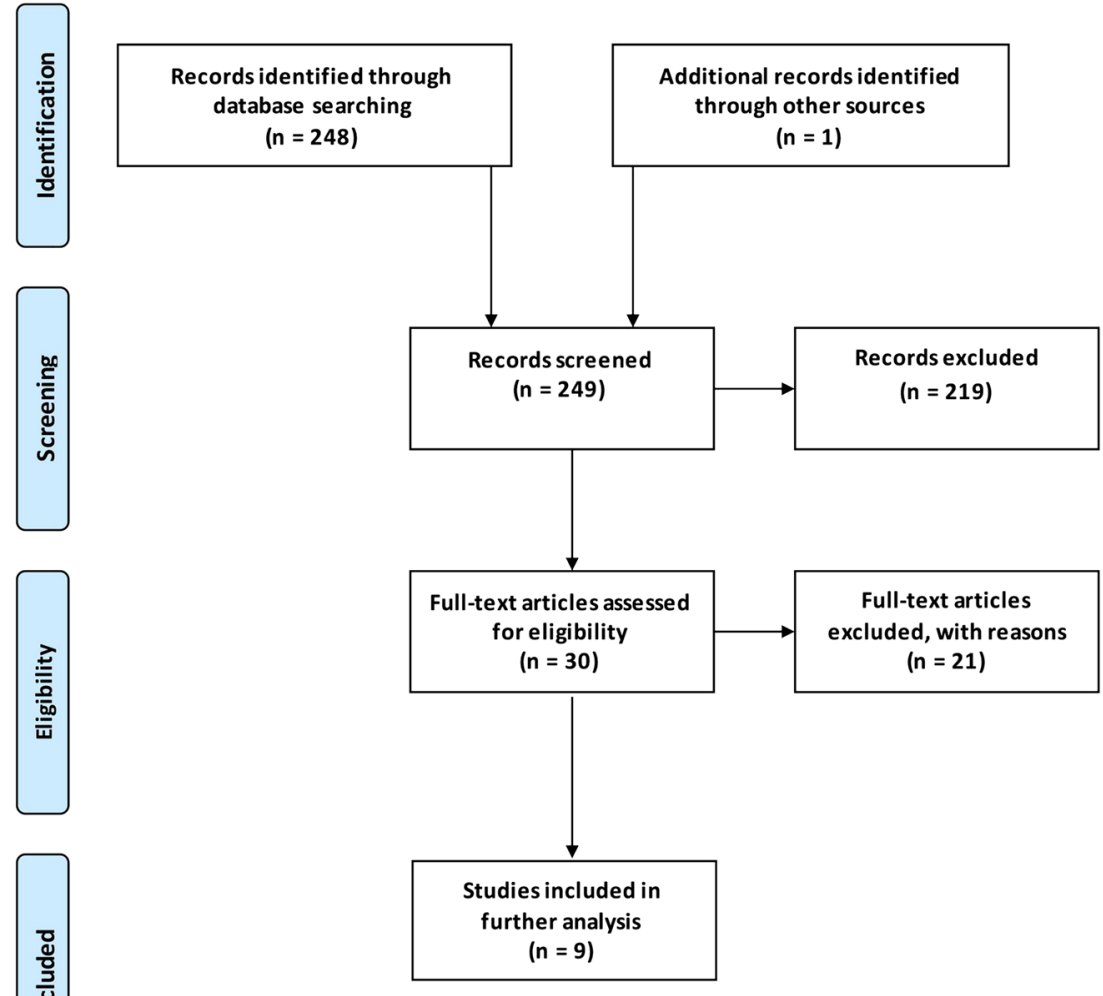


Table 1 Baseline characteristics of 87 poor-grade aSAH patients with or without PDC

\begin{tabular}{|c|c|c|c|}
\hline Characteristics, $n(\%)$ & PDC group & non-PDC group & $p$ value \\
\hline No. (male/female) & $38(10 / 28)$ & $49(15 / 34)$ & 0.812 \\
\hline Mean age (years) $( \pm S D)$ & $54( \pm 12)$ & $61( \pm 11)$ & 0.006 \\
\hline WFNS grade $V(\%)$ & $33(87)$ & $32(65)$ & 0.026 \\
\hline Fisher grade III-IV (\%) & $38(100)$ & $49(100)$ & 1.000 \\
\hline Mean aneurysm size in $\mathrm{mm}( \pm S D)$ & $12( \pm 8)$ & $8( \pm 6)$ & 0.009 \\
\hline Multiple aneurysms (\%) & $9(24)$ & $12(24)$ & 1.000 \\
\hline Clipping (\%) & $36(95)$ & $8(16)$ & $<0.0001$ \\
\hline Posterior circulation aneurysm (\%) & $0(0)$ & $17(35)$ & $<0.0001$ \\
\hline $\mathrm{ICH}(\%)$ & $26(68)$ & $13(27)$ & 0.0002 \\
\hline Dilated pupil (\%) & $22(58)$ & $13(27)$ & 0.0042 \\
\hline$S D C(\%)$ & $0(0)$ & $14(29)$ & 0.0002 \\
\hline Anticoagulation/antiplatelet drugs (\%) & $9(24)$ & $18(37)$ & 0.245 \\
\hline Hypertension (\%) & $13(34)$ & $20(41)$ & 0.657 \\
\hline Hospital stay in $d( \pm S D)$ & $34( \pm 32)$ & $33( \pm 28)$ & 0.877 \\
\hline Ventilation in $h( \pm S D)$ & $387( \pm 376)$ & $385( \pm 367)$ & 0.980 \\
\hline Favorable mRS at 6-month follow-up (\%) & $7(18)$ & $10(20)$ & 1.000 \\
\hline Favorable mRS at 1-year follow-up (\%) & $9(24)$ & $10(20)$ & 0.796 \\
\hline Favorable mRS at 2-year follow-up (\%) & $10(26)$ & $10(20)$ & 0.610 \\
\hline Mortality after 2 years (\%) & $21(55)$ & $25(51)$ & 0.829 \\
\hline
\end{tabular}

$I C H$ intracerebral hemorrhage, $m R S$ modified Rankin Scale, $(P) /(s) D C$ (primary)/(secondary) decompressive craniectomy, WFNS World Federation of Neurosurgical Societies; $p<0,05$ considered statistically significant aneurysms were found in $24 \%$ of the patients in each group $(p=1.00)$.

Prior use of anticoagulation/antiplatelet drugs and high blood pressure as pre-existing condition did not differ between the two groups: Nine of thirty-eight patients (24\%) in the PDC group were on anticoagulation/ antiplatelet therapy prior to ictus compared with eighteen of forty-nine patients $(37 \%)$ in the non-PDC group ( $p=$ $0.25)$. Pre-existing high blood pressure was diagnosed in thirteen of thirty-eight patients $(34 \%)$ versus twenty of forty-nine patients $(41 \%)(p=0.66)$.

The duration of mechanical ventilation and the duration of hospitalization did not differ between the groups (Table 1).

\section{Neurological outcome}

Outcome measures were assessed at 6 months, at 1 year, and at 2 years after aSAH. Follow-up data was available for all patients. Overall, after 2 years, 10 of 38 (26\%) patients who underwent PDC achieved a favorable outcome compared with 10 of $49(20 \%)$ patients in the control group $(p=0.61)$.

Mortality rate after 2 years did not differ between the two groups: $55 \%$ after PDC versus $51 \%$ in patients without PDC $(p=0.83)$. Outcome and mortality rates after 2 years of all patients are shown in Table 2.

\section{Matched-pair analysis}

In a matched-pair analysis of 38 patients (PDC group) versus 25 patients (non-PDC group), initial clinical status at presentation did not differ significantly (baseline characteristics and outcome are shown in Table 3). While initial status did not differ between the two groups, there was a trend towards better long-term neurological outcome in the PDC group compared with the non-PDC group $(p=0.1)$.

\section{Systematic literature review}

The search strategy is shown in Fig. 4. The initial MEDLINE search yielded a number of 248 studies. There was one additional record through checking the reference lists of the included studies. Of the 248 records screened, 29 full-text articles were assessed for eligibility, 9 of which met the inclusion criteria [3, 6, 8, 21, 22, 26, 27, 30, 38]. Data of the 9 included studies are summarized in Table 4 . The 9 included studies contained a total number of 165 DC patients in aSAH. Extracting the cases of PDC in poor-grade aSAH patients, a patient number of 131 left over. Mean age of this patient group was 53 years (SD 5.66) and the mean follow-up time was 11 months (SD 3.71). In total, nearly half of the patients (64 of 131 patients (49\%)) achieved a favorable functional longterm outcome. 
Table 2 Patient neurological outcome (mRS) and mortality after 2 years in single-center cohort

\begin{tabular}{lllll}
\hline & & $\begin{array}{l}\text { All patients }(\%) \\
n=87\end{array}$ & $\begin{array}{l}\text { PDC group (\%) } \\
n=38\end{array}$ & $\begin{array}{l}\text { non-PDC group (\%) } \\
n=49\end{array}$ \\
\hline Favorable & mRS 0 & $3(3.4)$ & $2(5.3)$ & $1(2.0)$ \\
& mRS 1 & $5(5.7)$ & $2(5.3)$ & $3(6.1)$ \\
& mRS 2 & $9(10.3)$ & $4(10.5)$ & $5(10.2)$ \\
Unfavorable & mRS 3 & $3(3.4)$ & $2(5.3)$ & $1(2.0)$ \\
& mRS 4 & $10(11.5)$ & $4(10.5)$ & $6(12.2)$ \\
& mRS 5 & $11(12.6)$ & $3(7.9)$ & $8(16.3)$ \\
& mRS 6 & $46(52.9)$ & $21(55.3)$ & $25(51.0)$ \\
& Fav. outcome (mRS & $20(23.0)$ & $10(26.3)$ & $10(20.4)$ \\
& $0-3)$ & $30(34.5)$ & $14(36.8)$ & $16(32.7)$ \\
& mRS 0-4 & $46(52.9)$ & $21(55.3)$ & $25(51.0)$ \\
\hline
\end{tabular}

$m R S$ modified Rankin Scale, $(P) D C$ (primary) decompressive craniectomy

\section{Discussion}

\section{Properties of PDC}

Patients with poor-grade aSAH often have poor prognosis with high case fatality and disability rates [4, 7, 23, 37]. The effect of DC in this selected subset of patients was reported in multiple studies [3, 6, 8, 9, 12, 13, 16-19, 21, 22, 24-27, 30, 33, 34, 36, 38]. An early decompression (PDC) may intensify the protective properties of DC: reducing elevated ICP immediately after bone flap removal and dura opening and furthermore leading to an improvement in tissue perfusion and oxygenation. The question of indication and right timing for decompressive craniectomy became subject of a controversial debate. In 2009, Güresir et al. [13] published a large cohort of 79 patients with decompressive craniectomy in subarachnoid hemorrhage. Their results indicated that DC might be warranted regardless of whether the patient suffers from bleeding, infarction, or brain swelling. The authors stated that the best time for DC must still be defined, but an early decompression seems to be beneficial, leading to favorable outcome in $25.3 \%$ of their patients.

\section{Encouraging outcome data after PDC}

Beside an approved life-saving effect, it is still debatable if an early decompression provides a better long-term functional outcome with lower rates of severe disability and dependency rates of patients.

In our single-center analysis of poor-grade aSAH patients, we compared the neurosurgical treatment course with and without performing PDC (Table 1); patients in the PDC group had a significantly worse clinical status at presentation (significant higher rate of mydriasis/cerebral herniation and additional ICH and significant higher number of WFNS grade 5 classified patients). This led to the assumption that these patients achieve worse neurological long-term outcome, but in fact, favorable outcome at 2 years post-hemorrhage did not differ significantly between the two groups.
Table 3 Baseline characteristics and outcome in matched-pair analysis

\begin{tabular}{llll}
\hline Characteristics, $n(\%)$ & PDC group & non-PDC group & $p$ value \\
\hline No. (male/female) & $38(10 / 28)$ & $25(6 / 19)$ & 1.00 \\
WFNS grade V (\%) & $33(87)$ & $18(72)$ & 0.19 \\
Fisher grade III-IV (\%) & $38(100)$ & $25(100)$ & 1.00 \\
ICH (\%) & $26(68)$ & $13(52)$ & 0.29 \\
Dilated pupil (\%) & $22(58)$ & $9(36)$ & 0.12 \\
Favorable mRS at 2-year follow-up (\%) & $10(26)$ & $2(8)$ & 0.10 \\
Mortality after 2 years (\%) & $21(55)$ & $15(60)$ & 0.80 \\
\hline
\end{tabular}

$I C H$ intracerebral hemorrhage, $m R S$ modified Rankin Scale, $(P) D C$ (primary) decompressive craniectomy, WFNS World Federation of Neurosurgical Societies; $p<0,05$ considered statistically significant 
Table 4 Summary of 9 studies after systematic review of the literature for PDC in poor-grade aSAH

\begin{tabular}{|c|c|c|c|c|c|c|c|}
\hline Authors and year & $\begin{array}{l}\text { DC patients } \\
(n)\end{array}$ & $\begin{array}{l}\text { Hunt and Hess } \\
4+5(\%)\end{array}$ & $\begin{array}{l}\text { PDC in } \\
\text { poor-grade } \\
\text { aSAH }(n)\end{array}$ & $\begin{array}{l}\text { Mean age } \\
\text { of PDC group } \\
\text { (years) }\end{array}$ & $\begin{array}{l}\text { Mean follow-up } \\
\text { (months) }\end{array}$ & $\begin{array}{l}\text { Mortality } \\
\text { of PDC group } \\
(\%)\end{array}$ & $\begin{array}{l}\text { Favorable } \\
\text { outcome } \\
\text { in PDC patients* } \\
(\%)\end{array}$ \\
\hline Arikan et al., 2010 & 11 & 100 & 11 & 45 & 12 & $45(5 / 11)$ & $36(4 / 11)$ \\
\hline $\begin{array}{l}\text { Buschmann et al., } \\
2007\end{array}$ & 38 & 82 & 18 & 50 & 12 & $33(6 / 18)$ & $44(8 / 18)$ \\
\hline $\begin{array}{l}\text { D'Ambrosio et al., } \\
2005\end{array}$ & 12 & 100 & 8 & 58 & 12 & $13(1 / 8)$ & $63(5 / 8)$ \\
\hline $\begin{array}{l}\text { Kazumata et al., } \\
2010\end{array}$ & 11 & 100 & 11 & 60 & 12 & $18(2 / 11)$ & $36(4 / 11)$ \\
\hline Lu et al., 2014 & 26 & 100 & 26 & 44 & 6 & $19(5 / 26)$ & $42(11 / 26)$ \\
\hline $\begin{array}{l}\text { Russegger et al., } \\
1993\end{array}$ & 19 & 100 & 19 & 57 & $\geq 3$ & $21(4 / 19)$ & $47(9 / 19)$ \\
\hline $\begin{array}{l}\text { Schirmer et al., } \\
2007\end{array}$ & 16 & 69 & 6 & 51 & 15 & $17(1 / 6)$ & $67(4 / 6)$ \\
\hline Smith et al., 2002 & 8 & 100 & 8 & 56 & 12 & $13(1 / 8)$ & $75(6 / 8)$ \\
\hline Zhao et al., 2015 & 24 & 100 & 24 & 52 & 12 & $29(7 / 24)$ & $58(14 / 24)$ \\
\hline TOTAL & 165 & & 131 & 53 & Median: 11 & $24(32 / 131)$ & $49(64 / 131)$ \\
\hline
\end{tabular}

*Favorable outcome: modified Rankin Scale (mRS) scores 0-3; Glasgow Outcome Scale (GOS) scores 4 and 5; extended Glasgow Outcome Scale (GOSE) scores 5-8; and classification as "fair", "good", and "excellent"

While historically these severely affected patients did not undergo any further treatment due to high mortality rates, our data reveals encouraging results of long-term outcome in these patients.

\section{Matched-pair analysis}

In a matched-pair analysis of 38 patients (PDC group) versus 25 patients (non-PDC group), where initial clinical status (WFNS grade, ICH, dilated pupil(s)/cerebral herniation) was equally distributed, results of favorable long-term neurological outcome reveal a trend towards a higher rate of favorable neurological outcome in the PDC group compared with the non-PDC group $(p=0.1)$. However, the patient cohort was too small to draw definitive conclusions. Baseline characteristics and outcome are shown in Table 3.

\section{PDC in literature review}

In the present systematic literature review, most of the authors came to the conclusion that aSAH patients who underwent an early DC seem to benefit the most regarding their long-term functional outcome. In 1993, Russegger et al. [26] recommended a "peracute aneurysm surgery," defined as that the operation has to be performed "immediately after hospitalization or diagnosis." All of their nineteen poor-grade aSAH patients underwent PDC immediately after admission (between 2 and $8 \mathrm{~h}$ after bleeding onset). Nine of the nineteen patients (47\%) reached a favorable outcome (defined as "fair," "good," or "excellent") after 1 year. Smith et al. [30] emphasized the potentially beneficial effect on the control of local and global ICP gradients and even proposed a prophylactic DC for the treatment of poor-grade aSAH patients with ICH. Seventy-five percent of their patients ( 6 out of 8 ) achieved a favorable outcome ("fair," "good," or "excellent") after 1 year, which is the highest rate of favorable outcome in the included studies. In D'Ambrosio et al. [8], the study group included 12 poor-grade aSAH patients who underwent DC. Excluded of meta-analysis had been 4 patients, who "returned to operating room for hemicraniectomy after initial aneurysm repair operation." Out of 8 PDC patients, 5 achieved a favorable outcome after 1 year (62.5\%; GOS $4+5)$, and they concluded that DC may be indicated "if performed early and in a specific subset of patients."

Buschmann et al. [6] presented 38 aSAH patients who underwent DC and summarized that patients "with progressive brain edema without radiological signs of infarctions and those with hematoma and consecutive ICP elevations might benefit most from DHC." For our data analysis, we extracted the 21 patients in "group 1: primary DHC," 18 of which were classified as poor grade on admission. Of these 18 patients, favorable outcome (GOS $4+5$ ) was achieved in $44 \%$. Schirmer et al. [27] stated that patients seem to have a better outcome, "in whom early decompression was performed within 48 hours after aneurysm rupture." They published a cohort of 16 patients who underwent DC, 11 of which were presenting as poor grade on admission. Of these 11 poor-grade patients, 6 underwent PDC (defined as "time to craniectomy": $d=0+d=1$ ), and 4 of them achieved a favorable outcome (67\%; mRS 0-3). Remarkably, Schirmer et al. showed that 
DC as treatment modality could significantly decrease refractory intracranial hypertension even in the absence of large intraparenchymal hemorrhage.

Furthermore, we could extract patient data about 11 poorgrade aSAH patients from Kazumata et al. [21]. Of these 11 patients who underwent an early external decompression, 4 patients achieved a favorable outcome (36\%; GOSE 5-8). Confirming our hypothesis, Kazumata et al. stated that an aggressive decompression in "acute stage may prevent significant postoperative brain swelling." From the studies of $\mathrm{Lu}$ et al. [22], Arikan et al. [3], and Zhao et al. [38], no separate patient data was needed to be extracted. In both studies, only cases of PDC in poor-grade aSAH patients were presented with rates of a favorable outcome of $42 \%$ ( $\mathrm{Lu}$ et al. [22]), $36 \%$ (Arikan et al. [3]), and even 58\% (Zhao et al. [38]). Moreover, Zhao et al. reported about their control group without DC, in which overall $57 \%$ of the patients achieved a favorable outcome, which lead the author to the statement that PDC "does not seem to be significantly associated with improved outcomes."

Beside these, Jussen et al. [19] published total number 11 PDC patients (DC in mean $2.6 \pm 1.4 \mathrm{~h}$ after admission), of which $25 \%$ made a good recovery compared with $12.5 \%$ in the secondary DC group. The author advocated an "ultra-early DC" especially for poor-grade patients with intracerebral mass lesion. Data of this publication was not included in the systematic literature review, because a long-term follow-up was not obtained in $16 \%$ of the patients.

Eventually, Jabbarli et al. [18] published the largest-to-date monocentric series of DC in aSAH. Their subgroup of PDC patients was subdivided into early ( $\leq 24 \mathrm{~h}$ after ictus) and delayed PDC. For all WFNS grade patients, a favorable outcome was achieved in $40 \%$ of the patients in the early PDC group and in $22 \%$ of the patients in the delayed PDC group. The publication has not been included in systematic literature review, because detailed patient data for the subgroup of poorgrade patients (Hunt and Hess $4+5$; WFNS $4+5$ ) could not be extracted. However, Jabbarli et al. stated that "especially SAH individuals with the admission WFNS $<5$ strongly benefit from early craniectomy," which led him to the conclusion that indication for DC should not be restricted only for poorgrade aSAH patients.

In total, out of the 131 poor-grade aSAH patients in the systematic literature review, nearly half of the patients achieved a favorable functional long-term outcome (49\%).

\section{Advantages of PDC}

Our results indicate that PDC may be warranted in this severely ill subset of patients. We believe that PDC may intensify the protective properties of $\mathrm{DC}$ through immediately reducing ICP, preventing secondarily ICP increase through allowing parenchymal swelling in the post-hemorrhagic period to a certain extent, thereby could avoid cerebral hypoperfusion. Furthermore, the risk of a second operation (secondary decompressive craniectomy) in the critical phase of illness is minimized. Even though there was a trend towards a better outcome for PDC patients, we also found PDC was not significantly associated with improved outcomes in our study cohort. One possible reason might be the worse initial clinical condition of patients in our PDC group (additional ICH, cerebral herniation, WFNS grade 5) compared with the PDC patients in literature research. Thus we had, for example, a high percentage of cases with cerebral herniation (58\%) and WFNS grade 5 (87\%), compared with other publications (e.g., Lu et al. [22]: $33 \%$ cerebral herniation and 46\% WFNS grade 5).

\section{Study limitations}

The study has several limitations. First of all, the retrospective design: Patient data in our single-center-cohort as well as in the included studies of the review of literature was acquired retrospectively. The sample size of our PDC group is quite small, but at least it is the largest PDC cohort of poor-grade aSAH patients with detailed information compared with the included studies from the literature review. The quite small number of patients limits the accuracy of the results. Furthermore, the patients have not been randomized in our cohort study - the decision-making varied according to the attending vascular neurosurgeon.

Furthermore, there are two main limits of our literature research: First, in the study populations, respectively the patient number of each study included for further analysis is small. Secondly, for most studies included, there is a lack of a consistent control group and thus a lack of comparisons demonstrating any potential advantage of PDC. One must consider that the relatively small number of patients does not justify formulating guidelines concerning indication of PDC. To draw definitive conclusion about indication and timing of DC, further prospective studies with standardized treatment protocols are needed.

However, we provide for the first time a single-center cohort analysis combined with a systematic literature review for $\mathrm{PDC}$ in poor-grade aSAH.

\section{Conclusions}

According to the current data, PDC may be a valid treatment option in the treatment of poor-grade aSAH. Despite a worse clinical status at presentation (significant higher rate of mydriasis and additional ICH), poor-grade aSAH patients who underwent PDC achieve favorable outcome in a significant number of patients. 
Summarizing the published cases of PDC, in nearly half of the patients, a favorable long-term functional outcome could be achieved.

An early decompression might prevent incontrollable elevated ICP and/or infarction due to vasospasm and thus may intensify the protective properties of DC through allowing parenchymal swelling in the post-hemorrhagic period to a certain extent and avoiding cerebral hypoperfusion.

Although the number of patients in this study is small, our findings suggest that PDC could lead to a better functional outcome. Therefore it should not be omitted in this severely ill subset of patients. To clarify a possible benefit of PDC on clinical outcome in poor-grade aSAH patients, a multicenter, prospective randomized controlled study (PICASSO trialPrimary decompressive craniectomy in aneurysmal subarachnoid hemorrhage, DRKS00017650) was initiated by the senior author as investigator-initiated trial.

Funding Open Access funding provided by Projekt DEAL.

\section{Compliance with ethical standards}

The authors report no conflict of interest concerning the materials or methods used in this study or the findings specified in this paper. All procedures performed in this study were in accordance with the ethical standards of the institutional and/or national research committee and with the 1964 Helsinki Declaration and its later amendments or comparable ethical standards. All aspects of this retrospective study were approved by the local ethics committee and for this type of study formal consent is not required.

Open Access This article is licensed under a Creative Commons Attribution 4.0 International License, which permits use, sharing, adaptation, distribution and reproduction in any medium or format, as long as you give appropriate credit to the original author(s) and the source, provide a link to the Creative Commons licence, and indicate if changes were made. The images or other third party material in this article are included in the article's Creative Commons licence, unless indicated otherwise in a credit line to the material. If material is not included in the article's Creative Commons licence and your intended use is not permitted by statutory regulation or exceeds the permitted use, you will need to obtain permission directly from the copyright holder. To view a copy of this licence, visit http://creativecommons.org/licenses/by/4.0/.

\section{References}

1. Aarabi B, Hesdorffer DC, Ahn ES, Aresco C, Scalea TM, Eisenberg HM (2006) Outcome following decompressive craniectomy for malignant swelling due to severe head injury. $\mathrm{J}$ Neurosurg 104:469-479. https://doi.org/10.3171/jns.2006.104.4. 469

2. Alotaibi NM, Elkarim GA, Samuel N, Ayling OGS, Guha D, Fallah A, Aldakkan A, Jaja BNR, de Oliveira Manoel AL, Ibrahim GM, Macdonald RL (2017) Effects of decompressive craniectomy on functional outcomes and death in poor-grade aneurysmal subarachnoid hemorrhage: a systematic review and meta-analysis. J Neurosurg 127:1315-1325. https://doi.org/10.3171/2016.9. JNS161383
3. Arikan F, Vilalta J, Romero FJ, Porta I, Martinez-Ricarte FR, Sahuquillo J (2010) Primary decompressive craniectomy in patients with aneurysmatic subarachnoid hemorrhage. Results of a pilot study in 11 cases. Neurocirugia (Astur) 21:452-460

4. Bailes JE, Spetzler RF, Hadley MN, Baldwin HZ (1990) Management morbidity and mortality of poor-grade aneurysm patients. J Neurosurg 72:559-566. https://doi.org/10.3171/jns.1990. 72.4.0559

5. Broderick JP, Brott TG, Duldner JE, Tomsick T, Leach A (1994) Initial and recurrent bleeding are the major causes of death following subarachnoid hemorrhage. Stroke 25:1342-1347

6. Buschmann U, Yonekawa Y, Fortunati M, Cesnulis E, Keller E (2007) Decompressive hemicraniectomy in patients with subarachnoid hemorrhage and intractable intracranial hypertension. Acta Neurochir 149:59-65. https://doi.org/10.1007/s00701-006-1069-x

7. Connolly ES Jr, Rabinstein AA, Carhuapoma JR, Derdeyn CP, Dion J, Higashida RT, Hoh BL, Kirkness CJ, Naidech AM, Ogilvy CS, Patel AB, Thompson BG, Vespa P (2012) Guidelines for the management of aneurysmal subarachnoid hemorrhage: a guideline for healthcare professionals from the American Heart Association/American Stroke Association. Stroke 43:1711-1737. https://doi.org/10.1161/STR.0b013e3182587839

8. D'Ambrosio AL, Sughrue ME, Yorgason JG, Mocco JD, Kreiter KT, Mayer SA, McKhann GM 2nd, Connolly ES Jr (2005) Decompressive hemicraniectomy for poor-grade aneurysmal subarachnoid hemorrhage patients with associated intracerebral hemorrhage: clinical outcome and quality of life assessment. Neurosurgery 56:12-19 dicussion 19-20

9. Dorfer C, Frick A, Knosp E, Gruber A (2010) Decompressive hemicraniectomy after aneurysmal subarachnoid hemorrhage. World neurosurgery 74:465-471. https://doi.org/10.1016/j.wneu. 2010.08.001

10. Ferguson S, Macdonald RL (2007) Predictors of cerebral infarction in patients with aneurysmal subarachnoid hemorrhage. Neurosurgery 60:658-667; discussion 667. https://doi.org/10. 1227/01.NEU.0000255396.23280.31

11. Guerra WK, Gaab MR, Dietz H, Mueller JU, Piek J, Fritsch MJ (1999) Surgical decompression for traumatic brain swelling: indications and results. J Neurosurg 90:187-196. https://doi.org/10. 3171/jns.1999.90.2.0187

12. Güresir E, Raabe A, Setzer M, Vatter H, Gerlach R, Seifert V, Beck J (2009) Decompressive hemicraniectomy in subarachnoid haemorrhage: the influence of infarction, haemorrhage and brain swelling. J Neurol Neurosurg Psychiatry 80:799-801. https://doi.org/10. 1136/jnnp.2008.155630

13. Güresir E, Schuss P, Vatter H, Raabe A, Seifert V, Beck J (2009) Decompressive craniectomy in subarachnoid hemorrhage. Neurosurg Focus 26:E4. https://doi.org/10.3171/2009.3. FOCUS0954

14. Güresir E, Vatter H, Schuss P, Oszvald A, Raabe A, Seifert V, Beck J (2011) Rapid closure technique in decompressive craniectomy. J Neurosurg 114:954-960. https://doi.org/10.3171/2009.12. JNS091065

15. Heuer GG, Smith MJ, Elliott JP, Winn HR, LeRoux PD (2004) Relationship between intracranial pressure and other clinical variables in patients with aneurysmal subarachnoid hemorrhage. J Neurosurg 101:408-416. https://doi.org/10.3171/jns.2004.101.3. 0408

16. Holsgrove DT, Kitchen WJ, Dulhanty L, Holland JP, Patel HC (2014) Intracranial hypertension in subarachnoid hemorrhage: outcome after decompressive craniectomy. Acta Neurochir Suppl 119: 53-55. https://doi.org/10.1007/978-3-319-02411-0_9

17. Hwang US, Shin HS, Lee SH, Koh JS (2014) Decompressive surgery in patients with poor-grade aneurysmal subarachnoid hemorrhage: clipping with simultaneous decompression versus coil embolization followed by decompression. Journal of cerebrovascular 
and endovascular neurosurgery 16:254-261. https://doi.org/10. 7461/jcen.2014.16.3.254

18. Jabbarli R, Oppong MD, Dammann P, Wrede KH, El Hindy N, Ozkan N, Muller O, Forsting M, Sure U (2017) Time is brain! Analysis of 245 cases with decompressive craniectomy due to subarachnoid hemorrhage. World neurosurgery 98:689-694 e682. https://doi.org/10.1016/j.wneu.2016.12.012

19. Jussen D, Marticorena S, Sandow N, Vajkoczy P, Horn P (2015) Ultra-early decompressive hemicraniectomy in aneurysmal intracerebral hemorrhage: a retrospective observational study. Minerva Anestesiol 81:398-404

20. Juttler E, Schwab S, Schmiedek P, Unterberg A, Hennerici M, Woitzik J, Witte S, Jenetzky E, Hacke W (2007) Decompressive surgery for the treatment of malignant infarction of the middle cerebral artery (DESTINY): a randomized, controlled trial. Stroke 38:2518-2525. https://doi.org/10.1161/STROKEAHA.107. 485649

21. Kazumata K, Kamiyama H, Yokoyama Y, Asaoka K, Terasaka S, Itamoto K, Osanai T (2010) Poor-grade ruptured middle cerebral artery aneurysm with intracerebral hematoma: bleeding characteristics and management. Neurol Med Chir 50:884-892

22. Lu TS, Guan JY, An CL (2014) Emergency microsurgery for aneurysmal subarachnoid hemorrhage coexisting with brain hernia. Turkish neurosurgery 24:695-698. https://doi.org/10.5137/10195149.JTN.9283-13.2

23. Macdonald RL (2014) Delayed neurological deterioration after subarachnoid haemorrhage. Nat Rev Neurol 10:44-58. https://doi.org/ 10.1038/nrneurol.2013.246

24. Otani N, Nawashiro H, Wada K, Nagatani K, Takeuchi S, Kobayashi H, Osada H, Suzuki T, Shima K (2013) Surgical results after primary decompressive craniectomy in poor-grade aneurysmal subarachnoid hemorrhage. Acta Neurochir Suppl 118:269272. https://doi.org/10.1007/978-3-7091-1434-6_51

25. Otani N, Takasato Y, Masaoka H, Hayakawa T, Yoshino Y, Yatsushige H, Miyawaki H, Sumiyoshi K, Chikashi A, Takeuchi S, Suzuki G (2008) Surgical outcome following decompressive craniectomy for poor-grade aneurysmal subarachnoid hemorrhage in patients with associated massive intracerebral or Sylvian hematomas. Cerebrovasc Dis 26:612-617. https://doi.org/10.1159/ 000165115

26. Russegger L, Twerdy K (1993) Peracute surgery of aneurysms with intracerebral hematomas. Neurochirurgia 36:37-43. https://doi.org/ 10.1055/s-2008-1053793

27. Schirmer CM, Hoit DA, Malek AM (2007) Decompressive hemicraniectomy for the treatment of intractable intracranial hypertension after aneurysmal subarachnoid hemorrhage. Stroke 38: 987-992. https://doi.org/10.1161/01.STR.0000257962.58269.e2

28. Schuss P, Hadjiathanasiou A, Borger V, Wispel C, Vatter H, Güresir E (2016) Poor-grade aneurysmal subarachnoid hemorrhage: factors influencing functional outcome-a single-center series. World neurosurgery 85:125-129. https://doi.org/10.1016/j. wneu.2015.08.046
29. Schwab S, Steiner T, Aschoff A, Schwarz S, Steiner HH, Jansen O, Hacke W (1998) Early hemicraniectomy in patients with complete middle cerebral artery infarction. Stroke 29:1888-1893

30. Smith ER, Carter BS, Ogilvy CS (2002) Proposed use of prophylactic decompressive craniectomy in poor-grade aneurysmal subarachnoid hemorrhage patients presenting with associated large Sylvian hematomas. Neurosurgery 51:117-124 discussion 124

31. Steiner T, Juvela S, Unterberg A, Jung C, Forsting M, Rinkel G (2013) European stroke organization guidelines for the management of intracranial aneurysms and subarachnoid haemorrhage. Cerebrovasc Dis 35:93-112. https://doi.org/10.1159/000346087

32. Tacconi L, Spinelli R, Signorelli F (2019) Subarachnoid hemorrhage in the eighties: to treat or not to treat. J Neurosurg Sci. Doi: https://doi.org/10.23736/S0390-5616.19.04743-X

33. Tuzgen S, Kucukyuruk B, Aydin S, Ozlen F, Kizilkilic O, Abuzayed B (2012) Decompressive craniectomy in patients with cerebral infarction due to malignant vasospasm after aneurysmal subarachnoid hemorrhage. J Neurosci Rural Pract 3:251-255. https://doi.org/10.4103/0976-3147.102598

34. Uozumi Y, Sakowitz O, Orakcioglu B, Santos E, Kentar M, Haux D, Unterberg A (2014) Decompressive craniectomy in patients with aneurysmal subarachnoid hemorrhage: a single-center matched-pair analysis. Cerebrovasc Dis 37:109-115. https://doi.org/10.1159/ 000356979

35. Vahedi K, Hofmeijer J, Juettler E, Vicaut E, George B, Algra A, Amelink GJ, Schmiedeck P, Schwab S, Rothwell PM, Bousser MG, van der Worp HB, Hacke W (2007) Early decompressive surgery in malignant infarction of the middle cerebral artery: a pooled analysis of three randomised controlled trials. Lancet Neurol 6:215-222. https://doi.org/10.1016/S1474-4422(07)700364

36. Wang HJ, Ye YF, Shen Y, Zhu R, Yao DX, Zhao HY (2014) Surgical treatment of poor grade middle cerebral artery aneurysms associated with large sylvian hematomas following prophylactic hinged craniectomy. J Huazhong Univ Sci Technolog Med Sci 34:716-721. https://doi.org/10.1007/s11596-014-1341-x

37. Zhao B, Rabinstein A, Murad MH, Lanzino G, Panni P, Brinjikji W (2017) Surgical and endovascular treatment of poor-grade aneurysmal subarachnoid hemorrhage: a systematic review and meta-analysis. J Neurosurg Sci 61:403-415. https://doi.org/10.23736/S03905616.16.03457-3

38. Zhao B, Zhao Y, Tan X, Cao Y, Wu J, Zhong M, Wang S (2015) Primary decompressive craniectomy for poor-grade middle cerebral artery aneurysms with associated intracerebral hemorrhage. Clin Neurol Neurosurg 133:1-5. https://doi.org/10.1016/j.clineuro. 2015.03.009

Publisher's note Springer Nature remains neutral with regard to jurisdictional claims in published maps and institutional affiliations. 